\title{
Knowledge of cervical cancer and HPV vaccine in Bangladeshi women: a population based, cross-sectional study
}

Jessica Yasmine Islam², Fatema Khatun², Anadil Alam², Farhana Sultana ${ }^{3,4}$, Afsana Bhuiyann ${ }^{5}$, Nazmul Alam, Laura Reichenbach ${ }^{7}$, Lena Marions ${ }^{8}$, Mustafizur Rahman $^{2}$ and Quamrun Nahar ${ }^{2^{*}}$ (i)

\begin{abstract}
Background: The objective of this study was to assess the level of knowledge of cervical cancer among Bangladeshi women and to assess their willingness to receive the human papillomavirus (HPV) vaccine.

Methods: A population-based, cross-sectional survey was conducted from July to December 2011 in one urban and one rural area of Bangladesh. A total of 2037 ever-married women, aged 14 to 64 years, were interviewed using a structured questionnaire. Data on socio-demographic characteristics and knowledge of cervical cancer were collected. Willingness to receive the HPV vaccine was assessed. Univariate analyses were completed using quantitative data collected. Multivariable logistic regression models were developed to identify factors associated with having heard of cervical cancer and the HPV vaccine.

Results: The majority of study participants reported to have heard of cervical cancer (urban: $89.7 \%$, rural $93.4 \% ; P=0$. 003). The odds of having heard of cervical cancer were significantly higher in urban women aged 35-44 years (aOR: 2. 92 (1.34-6.33) and rural women aged 25-34 years (aOR: 2.90 (1.24-6.73) compared to those aged less than 24 years. Very few women reported to have detailed knowledge on risk factors (urban:9.1\%, rural: 8.8\%) and prevention (urban: $6.4 \%$, rural: $4.4 \%)$ of cervical cancer. In our sample, one in five urban women and one in twenty rural women heard about a vaccine that can prevent cervical cancer. Among urban women, secondary education or higher (aOR: 3.48, 95\% Cl: 1.67-7.25), age of 20 years and above at marriage (aOR: $2.83,95 \% \mathrm{Cl}: 1.61-5.00)$, and high socioeconomic status (aOR: 2.25 , 95\% Cl: 1.28-3.95) were factors associated with having heard of the HPV vaccine. Willingness to receive the HPV vaccine among study participants either for themselves (urban: 93.9\%, rural: 99.4\%) or for their daughters (urban: 91.8\%, rural: 99.2\%) was high.

Conclusions: Detailed knowledge of cervical cancer among Bangladeshi women was found to be poor. Education on cervical cancer must include information on symptoms, risk factors, and preventive methods. Despite poor knowledge, the study population was willing to receive the HPV vaccine.
\end{abstract}

Keywords: Knowledge, Cervical cancer, Bangladesh, HPV vaccine

\footnotetext{
* Correspondence: quamrun@icddrb.org

${ }^{2}$ International Centre for Diarrhoeal Disease Research, Bangladesh (icddr,b),

68 Shaheed Tajuddin Ahmed Sharani, Mohakhali, Dhaka 1212, Bangladesh

Full list of author information is available at the end of the article
}

(c) The Author(s). 2018 Open Access This article is distributed under the terms of the Creative Commons Attribution 4.0 International License (http://creativecommons.org/licenses/by/4.0/), which permits unrestricted use, distribution, and reproduction in any medium, provided you give appropriate credit to the original author(s) and the source, provide a link to the Creative Commons license, and indicate if changes were made. The Creative Commons Public Domain Dedication waiver (http://creativecommons.org/publicdomain/zero/1.0/) applies to the data made available in this article, unless otherwise stated. 


\section{Background}

Globally, cervical cancer is the fourth most common cancer among women, with an estimated 528,000 new cases in 2012 [1]. A large majority of the global burden of cervical cancer occurs in less developed regions, where almost nine in ten (87\%) deaths are due to cervical cancer [1]. Such disproportionately high mortality rates have been attributed to several factors, including lack of availability of organized and high quality cervical cancer screening and treatment programs, lack of knowledge of cervical cancer, attitudinal barriers, and poor health systems infrastructure [2-5]. In Bangladesh, cervical cancer is the second most common cancer amongst women with an estimated 11,956 incident cases and 6582 deaths in 2012 [6].

Human papillomavirus (HPV) is the necessary cause of cervical cancer [7]. Persistent infection of approximately 15 high-risk HPV genotypes cause almost all cases of cervical cancer and its immediate precursor lesions [8]. Of these genotypes, HPV-16 and HPV-18 account for about $70 \%$ of global cervical cancer cases, with HPV-16 causing about 55-60\% and HPV-18 about 10$15 \%$ [9]. Similarly, according to our previously published findings, HPV-16 is the most common high-risk HPV genotype detected in Bangladeshi women [10]. This consistent global discovery has resulted in the major development of primary prevention of cervical cancer through HPV vaccination of young adolescents [11].

Currently, there are three types of HPV vaccines available in the global market: nonavalent vaccine "Gardasil - $9^{\mathrm{Tm}}$," quadrivalent "Gardasil ${ }^{\mathrm{Tm}}$ " and bivalent "Cervarix ${ }^{\mathrm{TM}}$." The HPV vaccine has demonstrated high degrees of efficacy with maximum clinical effectiveness and costeffectiveness in the target population of young adolescents, who are less likely to have been previously exposed to high-risk HPV genotypes [12, 13]. As these vaccines are highly effective before exposure to HPV, current guidelines prioritize adolescent girls as the primary target group for HPV vaccination [14].

While the vaccine has been shown to be efficacious, high vaccine uptake is essential for successful HPV vaccine program implementation [15]. Several factors have been attributed to high vaccine uptake among women, including knowledge of cervical cancer and the HPV vaccine, and its associated benefits [15], specifically in the United States (U.S.) and Australia. Additional studies conducted in the U.S. have shown that caregivers of vaccinated children are more likely to be knowledgeable of the HPV vaccine than caregivers of non-vaccinated children $[16,17]$. However, research conducted in developing countries, including Kenya and Nepal, have shown high HPV vaccine acceptability and willingness to receive the vaccine among women, despite low to moderate levels of knowledge of cervical cancer and the HPV vaccine $[18,19]$. Country-level data on knowledge of cervical cancer and attitudes towards the HPV vaccine among Bangladeshi women are imperative for resource allocation of cervical cancer primary prevention programs and to identify target groups for future educational programs. Data are particularly necessary as the HPV vaccine has been recently introduced in 2016 for the first time in Bangladesh by the Ministry of Health, with support from the Global Alliance for Vaccines and Immunizations (GAVI) [20].

Among Bangladeshi women, one previous report has documented high $(81 \%)$ awareness of cervical cancer, however, the majority (74\%) of these data were collected from women residing in rural areas and limited to women above the age of 30 years [21]. Additionally, indepth knowledge on cervical cancer, such as risk factors or symptoms, was not assessed. Data on knowledge of cervical cancer among a more representative sample, including those residing in urban areas and younger populations, are needed. Additionally, data on knowledge of HPV and the HPV vaccine among Bangladeshi women are currently not available in the literature. Therefore, the objective of this study was to assess women's knowledge of cervical cancer and willingness to receive the HPV vaccine among women residing in both rural and urban areas in Bangladesh. Additionally, factors associated with having heard of cervical cancer and the HPV vaccine were identified by urban and rural area of residence among this population. We hypothesized that knowledge of cervical cancer will be low and willingness to receive the HPV vaccine will be high, similar to other developing countries in the region.

\section{Methods}

\section{Study population}

Data for this study were collected during the baseline assessment of a population-based longitudinal cohort study developed to estimate the overall burden of HPV infection and risk factors associated with persistent infection among females in Bangladesh. This crosssectional survey was conducted between July and December of 2011 in one rural and urban area of Bangladesh. The urban area was located in Dhaka, the capital of Bangladesh. Since 2010, the International Centre for Diarrhoeal Disease Research, Bangladesh (icddr,b), an international research organization, has maintained a surveillance site for on-going research projects in Dhaka in one specific administrative ward (smallest administrative urban geographic unit), which covers a population of approximately 27,000 . To construct the sampling frame for the urban site, the administrative ward was divided into nine clusters, of which three were selected for this study. The rural area was located in Mirzapur, a sub-district of Tangail district. In Tangail, 
icddr,b has organized a demographic surveillance site since 2007. This surveillance site includes a population of approximately 240,000 and consists of eight unions (smallest administrative rural geographic unit). Of these eight unions, two were purposely selected and included in the sampling frame for the rural site. Systematic random sampling technique was used to select women in both areas.

Women who were ever-married, aged 14-64 years and residing in the study areas were invited to the study clinic for further assessment by the study physician. Women who were pregnant, post-partum, or with a history of hysterectomy, cervical cancer, uterine prolapse or with major psychological/psychiatric problems were excluded after history taking and/or clinical examination by the study physician. Pregnant women and women who were post-partum were excluded as cervical sampling implements may cause bleeding and interfere with the HPV test results. Further details regarding sampling methods, data collection, HPV testing and survey implementation methods have been previously published [10].

\section{Survey instrument}

Upon providing consent, women were interviewed using a structured and close-ended questionnaire, which collected demographic information, reproductive history, lifestyle factors such as condom and tobacco use, and knowledge of cervical cancer and attitudes towards the HPV vaccine. In order to assess knowledge of cervical cancer, participants were asked if they had "ever heard of a cancer called cervical cancer?" If participants responded, "Yes," then a series of questions to assess women's knowledge related to the disease and attitudes towards the HPV vaccination were asked, however, if a participant responded "No" then knowledge of cervical cancer and attitudes towards the HPV vaccine was not further assessed.

In order to assess knowledge, the following questions were asked: (1) "From where did you hear about cervical cancer?"; (2) "Do you know how a woman can get this cancer?"; (3) "If yes, how can a woman get this cancer?"; (4) "Do you think cervical cancer can be prevented?"; and (5) "If yes, how can it be prevented?" Possible responses to all knowledge questions were defined in the questionnaire, including an "Other" option. Participants were able to provide a free response if they chose "Other." Responses to "Other" were recoded and included in the analysis. Participants were able to provide more than one response for each question.

Next, participants were asked a series of questions to assess their attitudes towards the HPV vaccination. If a participant had previously indicated they had never heard of cervical cancer, then these questions were skipped. Questions related to attitudes towards the HPV vaccination included, (1) "Have you heard of a vaccine to prevent cervical cancer?"; (2) "Would you support a measure to prevent cervical cancer?"; (3) "If there was such a vaccine available, would you take the vaccine to prevent cervical cancer?"; (4) "Would you be willing to give your daughter such a vaccine?"; and (5) "Would you be willing to recommend the vaccine to others?" Participants were able to answers these questions with either "Yes," "No" or "Not Sure/Don't Know."

\section{Sample size}

The sample size necessary to carry out this study was calculated using the parent study's objective to assess the prevalence of HPV in the Bangladeshi population. Prior to our study, the prevalence of HPV in Bangladesh was unknown. Based on estimates of HPV prevalence from neighboring countries, we assumed the prevalence of HPV infection among the general female population in Bangladesh would be close to $8 \%$. We utilized the following formula to calculate the sample size [22]:

$$
n=\frac{Z^{2} P(1-P)}{d^{2}}
$$

Here $\mathrm{n}=$ sample size, $\mathrm{Z}=\mathrm{Z}$ statistic for a level of confidence, $\mathrm{P}=$ expected prevalence or proportion and $\mathrm{d}=$ precision. Using this formula, we calculated the necessary sample size for the urban and rural sites separately to account for potential differences in loss to follow-up. For both sites we used the following parameters to complete our estimates: $8 \%$ prevalence, $2 \%$ allowable error, and 95\% confidence intervals. For the rural site, we estimated our loss to follow-up may reach $20 \%$, including drop out due to pregnancy during the two-year follow-up period leading to a target sample size of 883 . For the urban site, we assumed loss to follow-up may reach $30 \%$, as residents of urban areas are more mobile than rural areas. Based on this assumption, the target sample size for the urban site was 1009 women.

\section{Data analysis}

Descriptive analyses were conducted to assess demographic characteristics of participants, by rural and urban area of residence. Frequency distributions were presented on background characteristics, including age, marital status, education, occupation, parity, and monthly household expenditure as a proxy measure for socioeconomic status. Test of significance was performed using Chi-square test at $5 \%$ level of significance. Multivariable logistic regression models were generated separately for urban and rural women to assess factors associated with "Ever heard of Cervical cancer" and "Ever heard of HPV vaccine" as dependent variables. Adjusted odds ratios (aORs) and its 95\% confidence 
intervals (CIs) were estimated. Variables of interest to include in the multivariable model were initially identified using the existing literature $[23,24]$. Next, these variables were assessed using univariate analyses. Any factor that provided a univariate $p$-value $<0.05$ for either the rural or urban model was included in the final multivariable regression models. The following variables were adjusted for in the models: age, education, occupation, age at marriage, husband's education, parity, socioeconomic status, oral pill use, abortion history, and condom use. Collinearity was assessed using the variance inflation factor (VIF) to ensure a strong linear relationship among independent variables included in the model was not present. Due to the sampling design and possible effect modification, data analyses were carried out separately for urban and rural samples. All statistical analyses were performed using STATA/SE 12.0.

\section{Results}

A total of 3354 eligible women were approached; 1855 in the urban area and 1499 in the rural area. Of the 1855 urban women approached, 1152 (62\%) agreed to participate. Among those who agreed to participate, 1113 (97\%) completed interviews. In the rural areas, 1159 of 1499 (77\%) eligible women agreed to participate and $924(80 \%)$ completed interviews. Common reasons included refused to take part in the study $(n=597 ; 18 \%)$, failure to attend scheduled interview located at project office $(n=330 ; 10 \%)$ or were found ineligible based on study exclusion criteria (pregnant, post-partum, or with a history of hysterectomy, cervical cancer, uterine prolapse or with major psychological/psychiatric) after examination conducted by the study physician at enrollment $(n=390 ; 12 \%)$.

\section{Background characteristics}

Table 1 presents socio-demographic characteristics of our study population in urban and rural areas in this study. Urban and rural women differed significantly on most socio-demographic characters except parity. In both urban and rural sites, the average age of women was 33 years. Significantly more women in the rural area reported they were married than their urban counterpart (98\% versus $90 \% ; p<0.001)$. Overall, women from the urban site were more educated, with an average of approximately 7 years of education compared to 5 years of education among rural women. $16 \%$ of urban women reported to work as a garment worker or housemaid compared to about $1 \%$ of rural women. Additionally, a higher proportion of urban women (31\%) reported a monthly expenditure of 20,000 BDT or greater compared to rural women (7\%). One-third of rural women were married at 14 years of age or younger. Urban women reported to have more educated husbands than rural women with an average of approximately 9 years' education compared to about 6 years respectively $(p<$ 0.001 ). In our sample, significantly more women in rural areas heard of cervical cancer compared to urban women $(93 \%$ versus $90 \%, p=0.003)$. Very few women reported to have ever had a cervical cancer screening test. There were significantly more women in the urban area who underwent cervical cancer screening compared to their rural counterpart $(3 \%$ versus $1 \%, \mathrm{p}<0.001)$. None of the women in this study reported to have previously received the HPV vaccine, based on self-report.

\section{Knowledge of cervical cancer and willingness to receive HPV vaccine}

Of the women who reported to have heard of cervical cancer $(n=1861)$, only one in ten reported knowing different ways of getting the disease $(n=182)$ (Table 2). Urban women reported the most common way of developing cervical cancer was sexual intercourse (33\%), which in rural women was "poor hygiene during menstruation" (22\%). "Sexual relationship other than husband" was the next common way of getting cervical cancer in both rural (20\%) and urban (21\%) women. Very few women (urban: 6\%, rural: $3 \%$ ) indicated, "not using a condom" as a way to develop cervical cancer.

Women's knowledge about prevention of cervical cancer was also very poor. Very few women believed that cervical cancer can be prevented (urban: 7\%, rural: 4\%). When asked about the ways this disease can be prevented, the majority thought that cleanliness (urban: $31 \%$, rural: $44 \%$ ) and maintaining a monogamous sexual relationship with their husband (urban: $32 \%$, rural: $20 \%$ ) was the most effective preventive measure. Over onethird of rural women mentioned medications as a method to prevent cervical cancer. $16 \%$ of urban women mentioned vaccination as a preventive method against cervical cancer compared to $5 \%$ of rural women. Very few women, both in urban and rural areas, were able to indicate "regular examination by doctor" as a method to prevent cervical cancer (Table 2). Of the 1861 women (91\%) who reported to have heard of cervical cancer, the majority of women heard about it from neighbors (urban: 55\%, rural: 66\%), relatives (urban: 31\%, rural: 45\%) and television (urban: 30\%, rural: 15\%) (Table 2).

Table 3 presents results from the multivariable logistic regression models of factors associated with having heard of cervical cancer. After controlling the effects of other factors in the models, we identified an effect of age among both urban and rural samples. Among urban women, the odds of having heard of cervical cancer were highest among those aged 35-44 years when compared to those aged less than 24 years (aOR: 2.92, CI: 1.346.33, $p=0.007)$. In rural women, the odds of having heard of cervical cancer were significant only for the age 
Table 1 Demographic characteristics of study population to assess knowledge of cervical cancer and the Human Papillomavirus (HPV) vaccine among ever-married Bangladeshi women $(n=2037)$

\begin{tabular}{|c|c|c|c|c|c|}
\hline \multirow[b]{2}{*}{ Characteristics } & \multicolumn{2}{|c|}{ Urban $(n=1113)$} & \multicolumn{2}{|c|}{ Rural $(n=924)$} & \multirow[b]{2}{*}{$P$-Value } \\
\hline & $\bar{n}$ & $\%$ & $\bar{n}$ & $\%$ & \\
\hline Age (in years) & & & & & 0.001 \\
\hline$<24$ & 242 & 21.7 & 195 & 21.2 & \\
\hline $25-34$ & 432 & 38.8 & 328 & 35.5 & \\
\hline $35-44$ & 246 & 22.1 & 275 & 29.8 & \\
\hline $45-64$ & 193 & 17.3 & 126 & 13.6 & \\
\hline Mean Age \pm SD & \multicolumn{2}{|c|}{$33.1 \pm 10.3$} & \multicolumn{2}{|c|}{$33.1 \pm 8.9$} & \\
\hline \multicolumn{5}{|l|}{ Marital Status } & $<0.001$ \\
\hline Married & 997 & 89.6 & 905 & 97.9 & \\
\hline Separated/Divorced/ Widowed & 116 & 10.4 & 19 & 2.1 & \\
\hline \multicolumn{5}{|l|}{ Religion } & $<0.001$ \\
\hline Muslim & 1098 & 98.7 & 796 & 86.1 & \\
\hline Non-Muslim & 15 & 1.4 & 128 & 13.6 & \\
\hline \multicolumn{5}{|l|}{ Education } & $<0.001$ \\
\hline No education & 212 & 19.1 & 272 & 29.4 & \\
\hline Primary & 270 & 24.3 & 244 & 26.4 & \\
\hline Secondary or more & 631 & 56.7 & 408 & 44.2 & \\
\hline Mean Education \pm SD & $6.7 \pm$ & & $4.9 \pm$ & & \\
\hline \multicolumn{5}{|l|}{ Occupation } & $<0.001$ \\
\hline Housewife & 769 & 69.1 & 860 & 93.1 & \\
\hline Garments worker / Housemaid & 176 & 15.8 & 6 & 0.7 & \\
\hline Other work ${ }^{b}$ & 168 & 15.1 & 58 & 6.3 & \\
\hline \multicolumn{5}{|l|}{ Socioeconomic Status $^{c}$} & $<0.001$ \\
\hline Low $(<10,000)$ & 248 & 22.3 & 542 & 58.7 & \\
\hline Medium (10,000-19,999) & 526 & 47.3 & 320 & 34.6 & \\
\hline High $(20,000+)$ & 339 & 30.5 & 62 & 6.7 & \\
\hline \multicolumn{5}{|l|}{ Age at Marriage (in years) } & $<0.001$ \\
\hline$<=14$ & 282 & 25.3 & 313 & 33.9 & \\
\hline $15-19$ & 579 & 52 & 515 & 55.7 & \\
\hline 20 or more & 252 & 22.6 & 96 & 10.4 & \\
\hline Mean Age at Marriage \pm SD & $17.1 \pm$ & & 16.0 & & \\
\hline \multicolumn{5}{|l|}{ Husband's Education } & $<0.001$ \\
\hline No Education & 125 & 11.2 & 294 & 31.8 & \\
\hline Primary & 157 & 14.1 & 206 & 22.3 & \\
\hline Secondary or more & 831 & 74.7 & 424 & 45.9 & \\
\hline Mean Education \pm SD & $8.9 \pm$ & & $5.5 \pm$ & & \\
\hline \multicolumn{5}{|l|}{ Parity } & 0.612 \\
\hline 0 & 76 & 6.8 & 63 & 6.8 & \\
\hline $1-2$ & 451 & 40.5 & 394 & 42.6 & \\
\hline $3+$ & 586 & 52.7 & 467 & 50.5 & \\
\hline Mean Parity \pm SD & $2.9 \pm$ & & $2.7 \pm$ & & \\
\hline
\end{tabular}


Table 1 Demographic characteristics of study population to assess knowledge of cervical cancer and the Human Papillomavirus (HPV) vaccine among ever-married Bangladeshi women $(n=2037)$ (Continued)

\begin{tabular}{|c|c|c|c|c|c|}
\hline \multirow[b]{2}{*}{ Characteristics } & \multicolumn{2}{|c|}{ Urban $(n=1113)$} & \multicolumn{2}{|c|}{ Rural $(n=924)$} & \multirow[b]{2}{*}{$P$-Value ${ }^{\mathrm{a}}$} \\
\hline & $n$ & $\%$ & $n$ & $\%$ & \\
\hline \multicolumn{6}{|l|}{ Oral Pill Usage } \\
\hline Ever & 874 & 78.5 & 799 & 86.5 & $<0.001$ \\
\hline Never & 239 & 21.5 & 125 & 13.5 & \\
\hline \multicolumn{6}{|l|}{ Abortion History } \\
\hline Ever & 417 & 37.5 & 91 & 9.9 & $<0.001$ \\
\hline Never & 696 & 62.5 & 833 & 90.2 & \\
\hline \multicolumn{6}{|l|}{ Tobacco Use } \\
\hline Ever & 292 & 73.8 & 235 & 74.5 & 0.681 \\
\hline Never & 821 & 26.2 & 689 & 25.4 & \\
\hline \multicolumn{6}{|l|}{ Condom Use } \\
\hline Ever & 574 & 51.6 & 301 & 32.6 & $<0.001$ \\
\hline Never & 539 & 48.4 & 623 & 67.4 & \\
\hline Ever Heard of Cervical Cancer & & & & & 0.003 \\
\hline Yes & 998 & 89.7 & 863 & 93.4 & \\
\hline No & 115 & 10.3 & 61 & 6.6 & \\
\hline Ever Underwent Cervical Cancer Screening & & & & & $<0.001$ \\
\hline Yes & 34 & 3.1 & 6 & 0.7 & \\
\hline No & 1079 & 96.9 & 918 & 99.4 & \\
\hline
\end{tabular}

${ }^{a}$ Calculated using chi-squared test

${ }^{b}$ Includes government and private service, business, daily wager, agriculture, tailor, poultry, handicrafts and tutor

${ }^{c}$ Monthly Expenditure BDT, 1US\$ = 78 BDT

group 25-34 years when compared to those aged less than 24 years (aOR: 2.90, CI: $1.24-6.73, p=0.014$ ).

Education was identified as a significant factor among urban women. Urban women with primary education (aOR: 2.44, CI: $1.33-4.49, p=0.004$ ) and secondary education or above (aOR: 3.76, CI: 1.97-7.18, $p<0.001$ ) had increased odds of hearing of cervical cancer when compared to urban women with no education. No significant effect of education was observed among rural women.

Parity was found to be associated with having heard of cervical cancer for urban women only. In particular, the odds of having heard of cervical cancer among urban women with three children or more was 5 times that of urban women with no children (aOR: 5.28, CI: 2.1213.15, $p=<0.001)$. Similarly, socioeconomic status was only associated with the having heard of cervical cancer among urban women. The odds of the outcome among urban women with a high socioeconomic status (SES) was 3.0 times that of the odds of urban women with a low SES (aOR: 3.00, CI: 1.42-6.34, $p=0.004$ ). And finally, ever condom usage among urban women was a significant factor associated with having heard of cervical cancer; the odds of having heard of cervical cancer was $67 \%$ higher among urban women who reported to have ever used a condom when compared to those who did not.

\section{Attitude towards HPV vaccination}

Twenty-one percent of urban women and only $3 \%$ of rural women reported to have heard of a vaccine that can prevent cervical cancer (Fig. 1). When asked if they would take a vaccine to prevent cervical cancer, almost all women said yes (urban: 94\%, rural: 99\%). The majority of women were also willing to recommend the vaccine to others (urban: 92\%, rural: 99\%). Participants who had a daughter were asked if they would be willing to provide such a vaccine to their daughters to which most women said yes (urban: 92\%, rural: 99\%) (Fig. 1).

Table 4 presents results of the multivariable logistic regression models to identify factors associated with having heard of the HPV vaccine. Overall, no association was identified with age after adjusting for covariates previously identified to be associated with the outcome among both urban and rural women. Education was associated with the outcome among urban women only; the odds of having heard of HPV vaccine among urban women with secondary education or above was 3.48 times the odds of those with no formal education (aOR: $3.48,95 \%$ CI: $1.67-7.25, p=0.001)$. Similarly, age at marriage was only associated with the outcome among urban women only. Among those married at both 1519 years (aOR: 2.18, 95\% CI: 1.32-3.60, $p=0.002$ ) and 
Table 2 Knowledge of ever-married Bangladeshi women of main risk factors and prevention measures associated with cervical cancer $(n=1861)^{a}$

\begin{tabular}{|c|c|c|c|c|}
\hline & \multicolumn{2}{|c|}{ Urban } & \multicolumn{2}{|c|}{ Rural } \\
\hline & $n$ & $\%$ & $\mathrm{n}$ & $\%$ \\
\hline \multicolumn{5}{|l|}{ Ways to Develop Cervical Cancer $(n=182)^{b}$} \\
\hline Sexual Intercourse & 33 & 32.7 & 11 & 13.6 \\
\hline Sexual relationship with other than husband & 21 & 20.8 & 16 & 19.8 \\
\hline Poor hygiene during Menstruation & 18 & 17.8 & 18 & 22.2 \\
\hline General poor hygiene & 6 & 6.0 & 8 & 10.0 \\
\hline Husband has a disease & 5 & 4.9 & 4 & 4.9 \\
\hline Food / Water & 1 & 0.9 & 3 & 3.7 \\
\hline Not using a condom & 6 & 5.9 & 2 & 2.5 \\
\hline Skin-to-skin contact & 3 & 2.9 & 9 & 11.1 \\
\hline \multicolumn{5}{|c|}{ Preventive Methods against Cervical Cancer $(n=121)^{c}$} \\
\hline Sexual relationship only with husband & 23 & 32.4 & 8 & 19.5 \\
\hline Cleanliness & 22 & 30.9 & 18 & 43.9 \\
\hline Vaccination & 11 & 15.5 & 2 & 4.9 \\
\hline One-time examination by Doctor & 10 & 14.1 & 5 & 12.2 \\
\hline Condom Use & 9 & 12.7 & 3 & 7.3 \\
\hline Regular Examination by doctor & 3 & 4.2 & 0 & 0.0 \\
\hline Medications & 2 & 2.8 & 13 & 31.7 \\
\hline Eating Well & 1 & 1.4 & 0 & 0.0 \\
\hline \multicolumn{5}{|l|}{ Source of Knowledge of Cervical Cancer } \\
\hline Neighbors & 549 & 55.0 & 572 & 66.3 \\
\hline Relatives (besides husband) & 304 & 30.5 & 389 & 45.1 \\
\hline Television & 301 & 30.2 & 127 & 14.7 \\
\hline Doctor & 123 & 12.3 & 66 & 7.7 \\
\hline Other Health Professional & 126 & 12.6 & 66 & 7.7 \\
\hline News paper & 45 & 4.5 & 4 & 0.5 \\
\hline Colleagues & 29 & 2.9 & 5 & 0.6 \\
\hline Radio & 12 & 1.2 & 5 & 0.6 \\
\hline Friends & 13 & 1.3 & 1 & 0.1 \\
\hline Husband & 3 & 0.3 & 8 & 0.9 \\
\hline
\end{tabular}

a Percent may exceed $100 \%$ as multiple answers are possible and sample is limited to those who reported to have heard of cervical cancer

${ }^{b}$ Sample is limited to those who reported to know how a woman can get cervical cancer $(n=182)$

'Sample is limited to those who reported to know about preventive methods for cervical cancer $(n=121)$

20 years or above (aOR: 2.83, 95\% CI: $1.61-5.00, p<$ 0.001 ), the odds were more than doubled when compared to those married at 14 years or below. Finally, high socioeconomic status was associated with having heard of HPV vaccine among urban women as well (aOR: 2.25 , 95\% CI: $1.28-3.95, p=0.005)$.

\section{Discussion}

In Bangladesh, cervical cancer remains the second most common cancer among women despite global advances in its prevention and treatment. Knowledge of cervical cancer and primary prevention through vaccination is low, indicating a major public health concern for the nation. Our study found that while a large majority of participants $(\sim 90 \%)$ were aware of cervical cancer, less than $10 \%$ had in-depth knowledge of the causes of cervical cancer and potential preventive measures in place. Additionally, participants reported very limited knowledge of the HPV vaccine, particularly rural women. This is the first population-based study conducted in Bangladesh to demonstrate widespread acceptance of HPV vaccination among ever-married adult Bangladeshi women, for both themselves and for their daughters.

To our knowledge, only one other study, the Bangladesh Midlife Women's Health Study (BMWHS) has been previously conducted in Bangladesh to assess women's knowledge of cervical cancer [21]. However, the focus of the BMWHS's research question was on cervical cancer screening and there was no assessment of awareness or acceptability of HPV vaccination presented. Eighty-one percent of the study population of BMWHS reported to have ever heard of cervical cancer, which is lower than both our rural (90\%) and urban population's (93\%) awareness. The investigators of this study did not delve further into knowledge of cervical cancer and limited their assessment to five questions which focused on cervical cancer screening. In contrast to our study, the investigators reported that $8.3 \%$ of their study population had previously undergone cervical cancer screening. This is particularly interesting as the majority (73\%) of their study sample was from rural areas of Bangladesh. In our study, only $3.1 \%$ of urban and $0.7 \%$ of rural women reported to have ever undergone cervical cancer screening. Findings from our analysis regarding screening rates are comparable to other surveys conducted in developing countries, particularly the South-Asian subcontinent [25].

The results of our cross-sectional study are consistent with other assessments of knowledge and acceptability of HPV vaccine knowledge conducted in low- and middleincome countries. Previous studies have reported both low levels of cervical cancer knowledge and high willingness to receive the HPV vaccine to prevent the development of cervical cancer from HPV [19, 26-31]. For example, in Nepal, previous reports have indicated that overall about half of women were aware of cervical cancer, with a higher awareness among urban Nepali women [19]. In-depth knowledge of cervical cancer was low, however, willingness to have their children vaccinated against HPV was high. In India, levels of knowledge of cervical cancer and acceptance of the HPV vaccine vary vastly by region [32]. In southern India, previous reports have shown that about one-third of women have heard of HPV while only $15 \%$ have heard of cervical cancer [33]. Additionally, only $46 \%$ of women were accepting of vaccination. Research 
Table 3 Factors associated with having heard of cervical cancer among ever-married Bangladeshi women $(n=2037)$

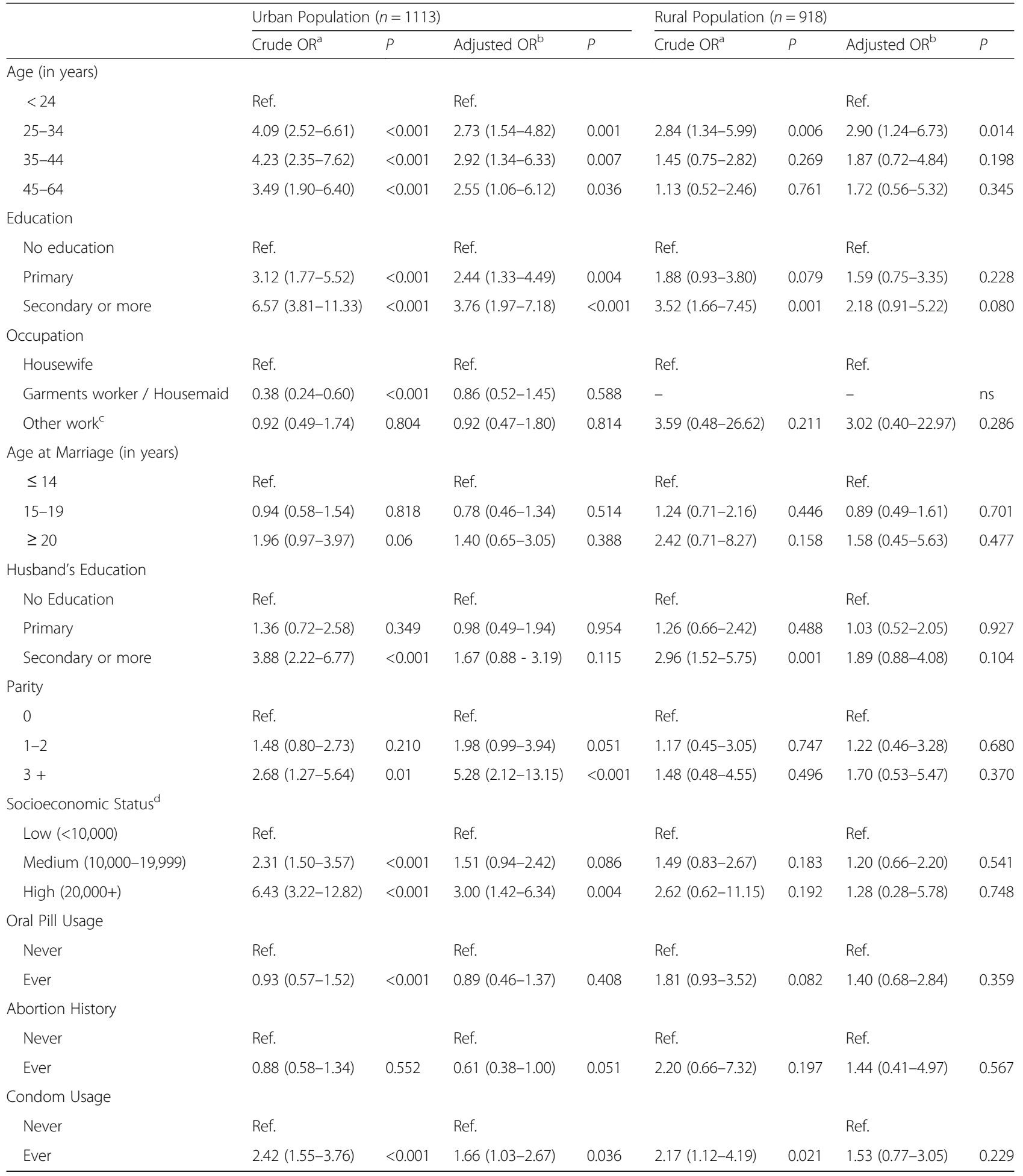

${ }^{a}$ Adjusted for age

${ }^{b}$ Adjusted for age, education, occupation, age at marriage, parity, oral pill usage, abortion history, socioeconomic status (income), condom use,

husband's education

Includes government and private service, business, daily wager, agriculture, tailor, poultry, handicrafts and tutor

${ }^{\mathrm{d}}$ Monthly Expenditure BDT, 1US\$ $=78$ BDT 


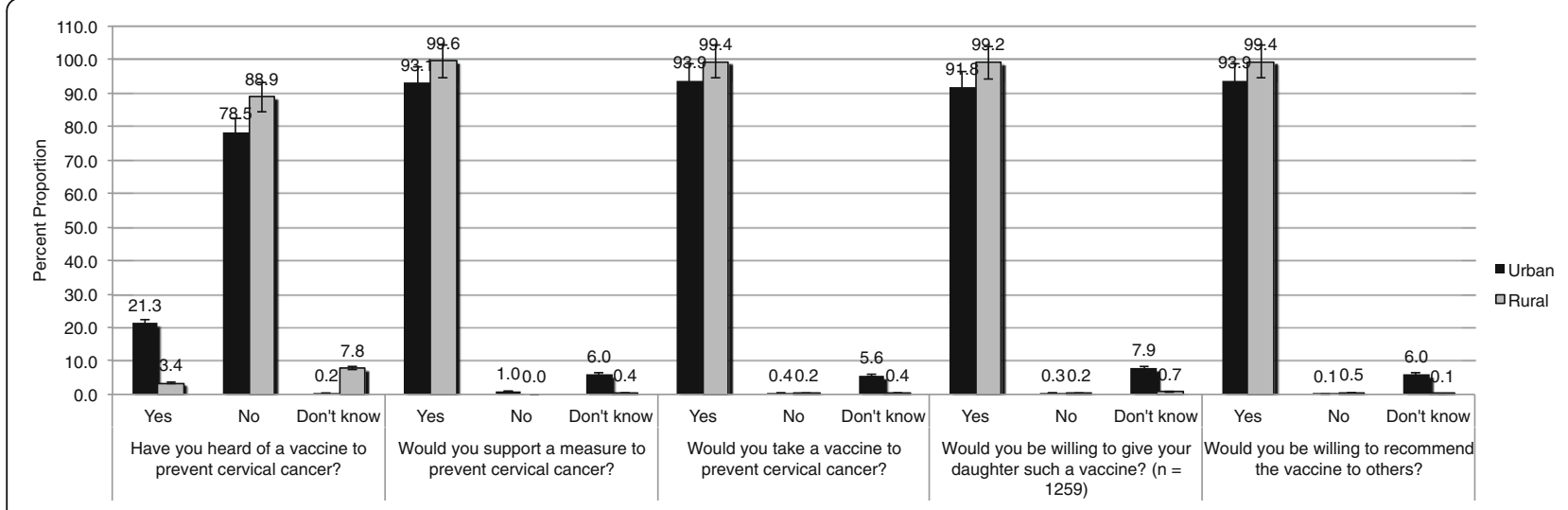

Fig. 1 Willingness to vaccinate against cervical cancer among ever-married Bangladesh women $(n=1861)$

conducted in northern Indian among young schoolattending girls (12-22 years of age) depicts low awareness (15\%) of HPV and cervical cancer, and low acceptance (13\%) of the HPV vaccination [34]. Although cervical cancer is the second-leading cause of cancer deaths among women in India [6] and the HPV vaccine is available in the Indian market, uptake is low due to low awareness and knowledge. Efforts should be made in Bangladesh to avoid a similar scenario and resources should be allocated to a wide-spread and culturally sensitive educational campaign to market the HPV vaccine as a vaccine against cancer for maximum uptake.

The results of our study provide important insight into sources of knowledge commonly utilized by Bangladeshi women to obtain information related to health, specifically cervical cancer and the HPV vaccine. The majority of both urban and rural participants reported to have heard of cervical cancer from neighbors, family members, and television programs. Future preventive programming can utilize television as a media source to reach a broader audience [35]. Data from this study also showed the minimal impact health professionals have on the population in terms of cervical cancer education: Only $12 \%$ of urban and $8 \%$ women reported to have heard of cervical cancer from a physician. Efforts should be made to coordinate all stakeholders, including physicians and other health professionals, in the implementation of successful HPV vaccine programs. Future research should assess levels of knowledge of cervical cancer and its preventative services among health care providers. This is of particular significance as previous literature shows health professionals play a key role in vaccine uptake and that physician recommendation is the strongest predictor of HPV vaccine uptake among adolescents [36].

A limited number of participants were able to identify different risk factors of cervical cancer. Participants who did provide a response for this question most frequently chose unhygienic menstrual practices, sexual intercourse, and a sexual relationship with someone other than their husband as potential ways to develop cervical cancer. Low condom use was not often chosen, indicating that the population is not aware of the etiology of HPV and cervical cancer. This may limit future HPV vaccine programming, as the population may not recognize the association between sexually transmitted infections (STIs) and cervical cancer, and opt out of receiving the vaccination. However, previous literature has also indicated that the association between STIs and cervical cancer has hindered efforts to promote the HPV vaccine in the population [37]. In several countries, a frequently identified barrier to HPV vaccination has been parental fears that the vaccine may lead to sexual promiscuity [38]. This is a vital concern and practitioners involved in primary care, school-based health services, and adolescent health should be engaged to avoid the potential spread of misinformation regarding the safety and efficacy of the vaccine. Future implementation efforts should include culturally appropriate educational interventions through the media, particularly the television, in order to better inform the population of the association between HPV and cervical cancer.

Similarly, only a small proportion of participants were able to provide responses regarding preventive methods against cervical cancer. The majority of participants chose medications, one-time examination by doctor, cleanliness, and maintaining a monogamous sexual relationship with their husband. Only a limited number of the respondents were able to correctly choose vaccination and regular examination by a physician. This finding further underscores the need for widespread educational interventions on cervical cancer and associated factors, such as risk behaviors and preventive methods. Such educational interventions can be targeted to groups who were identified to be less likely to have heard of cervical cancer based on multivariable analyses. These groups include: younger women in urban and rural areas, women with either no or low education in urban areas and rural areas, urban women with low income, and urban women who do not use condoms. 
Table 4 Factors associated with having heard of HPV Vaccine among ever-married Bangladeshi women $(n=2037)$

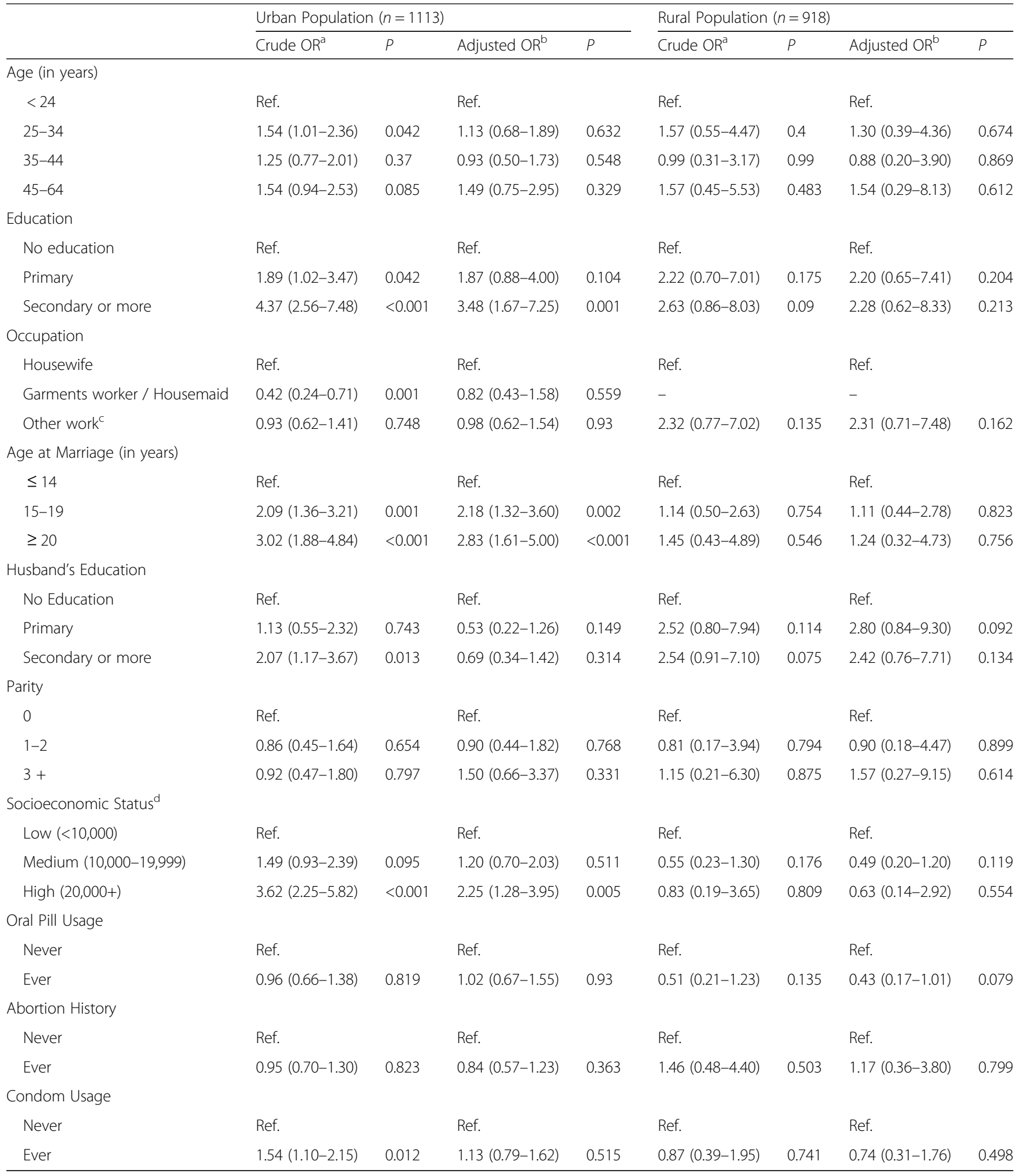

${ }^{a}$ Adjusted for age

${ }^{\text {b} A d j u s t e d ~ f o r ~ a g e, ~ e d u c a t i o n, ~ o c c u p a t i o n, ~ a g e ~ a t ~ m a r r i a g e, ~ p a r i t y, ~ o r a l ~ p i l l ~ u s a g e, ~ a b o r t i o n ~ h i s t o r y, ~ s o c i o e c o n o m i c ~ s t a t u s ~(i n c o m e), ~ c o n d o m ~ u s e, ~}$

husband's education

'Includes government and private service, business, daily wager, agriculture, tailor, poultry, handicrafts and tutor

${ }^{\mathrm{d}}$ Monthly Expenditure BDT, 1 US\$ $=78$ BDT 
Although findings from this study are novel and timely for successful HPV vaccine program implementation, several limitations should be taken into consideration when interpreting these results. Participants included in this study resided in surveillance sites of icddr,b. where they have frequently participated in various public health initiatives and research projects. This frequent exposure to public health programming may explain the population's widespread willingness to receive the HPV vaccination or a vaccine to prevent cervical cancer. As such, this sample may not be representative of the entire population, however, one can expect even lower knowledge in the broader population outside of the surveillance site. Additionally, questions included in this survey were close-ended; openended questions may have provided the opportunity to better assess cervical cancer and HPV related knowledge, perceived risk and awareness, especially when no prior data were available for this population.

The high level of willingness to receive a vaccine to prevent cervical cancer despite low knowledge of cervical cancer presents potential ethical issues and underscores the need to provide educational programs. This will ensure that Bangladeshi women are able to make informed decisions on their health and that of their families. Additionally, in the absence of accessible regular screening programs, the implementation of an HPV immunization program should be a public health priority in Bangladesh. In our study population, only $1.9 \%$ of the entire sample had previously undergone screening for cervical cancer. This finding is consistent with previous literature published in 2012, which estimated that only $1.1 \%$ of the women in Bangladesh had previously undergone cervical cancer screening based on data collected in 2003 [25]. Based on these results, it is reasonable to conclude that rates of cervical cancer screening have not improved over the last decade in Bangladesh. Previous studies have shown that low awareness and socioeconomic barriers can potentially lead to underutilization of screening services for women. Education of women by healthcare workers is an important factor for increasing screening rates [39]. Future research is needed to explore the level of knowledge of cervical cancer in other populations at high risk.

\section{Conclusions}

This study provides the first population-based assessment of willingness to receive the HPV vaccine. These findings are timely as the Government of Bangladesh has recently obtained support from GAVI to provide a national HPV vaccine program to school-aged adolescent girls. The findings from this study provide the necessary countryspecific evidence for the development of this program. Despite high levels of awareness of cervical cancer, indepth knowledge of causes of cervical cancer and how it can be prevented is low. Additionally, cervical cancer screening was very low in this population. These findings underscore the necessity for culturally appropriate and targeted educational interventions to improve knowledge of cervical cancer causes and its primary prevention through the HPV vaccine. Despite low knowledge about the disease and its prevention, there was a high level of willingness to receive a vaccine to prevent cervical cancer. As such, this survey suggests that the HPV vaccine would likely be an accepted addition to routine vaccinations in Bangladesh. Findings from this study have important implications for designing and implementing HPV vaccine programs, and educational efforts in the country.

\section{Abbreviations}

aOR: Adjusted Odds Ratio; BDT: Bangladeshi Taka; BMWHS: Bangladesh Midlife Women's Health Study; Cl: Confidence Interval; GAVI: Global Alliance for Vaccines and Immunizations; HPV: Human Papillomavirus; icddr,b: International Center for Diarrheal Disease Research, Bangladesh; OR: Odds Ratio; SES: Socioeconomic status; STIs: Sexually transmitted infections; VIF: Variance inflation factor

\section{Acknowledgements}

The authors of this paper would like to acknowledge the Swedish International Development Cooperation Agency (SIDA) for their funding support of this research project. Additionally, icddr,b and this research group gratefully acknowledges the following donors for their unrestricted support: Government of the People's Republic of Bangladesh, Global Affairs Canada (GAC), Swedish International Development Cooperation Agency (Sida) and UK Government (UKAid). This research group would also like to acknowledge the Kumudini Hospital, Mirzapur, Tangail and Concerned Women for Family Development, Dhaka for providing support and office space for research personnel at the respective study sites. We appreciate the support received from Bangabandhu Sheikh Mujib Medical University (BSMMU) for cervical cytology test and the services provided to the study women with cytological abnormalities. We thank Dr. Firdausi Qadri, Dr. ASG Faruque and Dr. Shams El Arifeen of icddr,b for allowing us to use surveillance data to create sampling frame for the study.

\section{Funding}

This work was funded by the Swedish International Development Cooperation Agency (Sida, www.sida.org): Sida contribution numbers 54100020 and 51060029. The funders had no role in study design, data collection and analysis, decision to publish, or preparation of the manuscripts.

\section{Availability of data and materials}

The dataset supporting the conclusions of this article should be requested by the corresponding author per the Internal Data Policy of icddr,b to access data. This Internal Data Policy governs the rights and responsibilities of icddr,b its employees and those scientists visiting in an official capacity regarding access to and ownership, authorship and archiving of data collected in icddr,b's surveillance systems, research protocols, hospital, clinical or laboratory records or statistics, surveys, training activities and any other data that (1) have intellectual value, and (2) are generated through activities of icddr,b. Only those data that ICDDR,B's Internal Data Policy, donor and publisher requirements, and ethical considerations permit will be made publicly available in the ICDDR,B Data Centre. Data are available upon request from the Research \& Clinical Administration and Strategy (RCAS) of icddr,b (http://www.icddrb.org/) for researchers who meet the criteria for access to confidential data.

\section{Authors' contributions}

Conceived and designed the experiment: JYI, FS, AA, FK, NA, LR, LM, MR, QN. Performed the experiments: JYI, FS, AA, FK, NA, LR, LM, MR, QN. Analyzed the data: JYI, QN. Contributed reagents/materials/analysis tools: FS, AA, FK, NA, $L R$, QN. Contributed to the writing of the manuscript: JYI, FS, AA, FK, AB, NA, $L R, L M, M R, Q N$. All authors read and approved the final manuscript. 


\section{Ethics approval and consent to participate}

Informed written consent was taken from women aged 18-64 years of age, whereas informed written assent was taken from women aged 14-17 years. For the latter group, the assent form was read out to these women in the presence of their parents/legal guardians. If agreed, the assent form was then signed by the participants in the presence of their parents/guardians. The parents or guardians also signed the same form. The study protocol was approved by the Ethical Review Committee of icddr,b.

\section{Consent for publication}

Not applicable.

\section{Competing interests}

The authors declare that they have no competing interests.

\section{Publisher's Note}

Springer Nature remains neutral with regard to jurisdictional claims in published maps and institutional affiliations.

\begin{abstract}
Author details
'Department of Epidemiology, Gillings School of Global Public Health, University of North Carolina at Chapel Hill, Chapel Hill, North Carolina, USA. ${ }^{2}$ International Centre for Diarrhoeal Disease Research, Bangladesh (icddr,b), 68 Shaheed Tajuddin Ahmed Sharani, Mohakhali, Dhaka 1212, Bangladesh. ${ }^{3}$ Centre for Epidemiology and Biostatistics, Melbourne School of Population and Global Health, The University of Melbourne, 207 Bouverie Street, Parkville, VIC 3010, Australia. ${ }^{4}$ Registries and Research, Victorian Cytology Service Registries, Level 6, 176 Wellington Parade, East Melbourne, VIC 3002, Australia. ${ }^{5}$ London North West Healthcare NHS Trust, London, UK. ${ }^{6}$ University of Montreal Hospital Research Centre (CR-CHUM), Montreal, QC, Canada. ${ }^{7}$ Population Council, Washington, DC, USA. ${ }^{8}$ Department of Clinical Science and Education, Karolinska Institutet, Stockholm, Sweden.
\end{abstract}

Received: 4 May 2016 Accepted: 3 January 2018

\section{Published online: 11 January 2018}

\section{References}

1. Ferlay J, Soerjomataram I, Dikshit R, Eser S, Mathers C, Rebelo M, Parkin DM Forman D, Bray F. Cancer incidence and mortality worldwide: sources, methods and major patterns in GLOBOCAN 2012. Int J Cancer. 2015;136(5):E359-86.

2. Poole DN, Tracy JK, Levitz L, Rochas M, Sangare K, Yekta S, Tounkara K, Aboubacar B, Koita O, Lurie M, et al. A cross-sectional study to assess HPV knowledge and HPV vaccine acceptability in Mali. PLoS One. 2013;8(2):e56402.

3. Denny L. The prevention of cervical cancer in developing countries. BJOG : an international journal of obstetrics and gynaecology. 2005;112(9):1204-12.

4. Leyva M, Byrd T, Tarwater P. Attitudes towards cervical cancer screenng: a study of beliefs among women in Mexico. Californian Journal of Health Promotion. 2006;4(2):13-24.

5. Markovic M, Kesic $V$, Topic L, Matejic B. Barriers to cervical cancer screening: a qualitative study with women in Serbia. Soc Sci Med. 2005;61(12):2528-35.

6. GLOBOCAN 2012: Estimated Cancer Incidence, Mortality and Prevalence Worldwide in 2012 [http://globocan.iarc.fr/Pages/fact_sheets_population.aspx].

7. Walboomers JM, Jacobs MV, Manos MM, Bosch FX, Kummer JA, Shah KV, Snijders PJ, Peto J, Meijer CJ, Munoz N. Human papillomavirus is a necessary cause of invasive cervical cancer worldwide. J Pathol. 1999;189(1):12-9.

8. Schiffman M, Castle PE, Jeronimo J, Rodriguez AC, Wacholder S. Human papillomavirus and cervical cancer. Lancet (London, England). 2007; 370(9590):890-907.

9. de Sanjose S, Quint WGV, Alemany L, Geraets DT, Klaustermeier JE, Lloveras B, Tous S, Felix A, Bravo LE, Shin HR, et al. Human papillomavirus genotype attribution in invasive cervical cancer: a retrospective cross-sectional worldwide study. The Lancet Oncology. 2010;11(11):1048-56.

10. Nahar Q, Sultana F, Alam A, Islam JY, Rahman M, Khatun F, Alam N, Dasgupta SK, Marions L, Ashrafunnessa, et al. Genital human papillomavirus infection among women in Bangladesh: findings from a population-based survey. PLoS One. 2014;9(10):e107675.

11. WHO Guidelines for Screening and Treatment of Precancerous Lesions for Cervical Cancer Prevention. Geneva: World Health Organization; 2013. http://www.who.int/reproductivehealth/publications/cancers/screening_ and_treatment_of_precancerous_lesions/en/.
12. Castle PE, Maza M, Prophylactic HPV. Vaccination: past, present, and future. Epidemiol Infect. 2016:144(3):449-68.

13. Gilmer LS. Human Papillomavirus Vaccine Update. Primary care. 2015;42(1): $17-32$.

14. Uddin N, Hasan MR, Hossain MM, Sarker A, Nazmul Hasan AHM, Mahmudul Islam AFM, Chowdhury MMH, Rana MS. In vitro a-amylase inhibitory activity and in vivo hypoglycemic effect of methanol extract of Citrus Macroptera Montr. Fruit. Asian Pacific journal of tropical biomedicine. 2014;4(6):473-9.

15. Kessels SJ, Marshall HS, Watson M, Braunack-Mayer AJ, Reuzel R, Tooher RL. Factors associated with HPV vaccine uptake in teenage girls: a systematic review. Vaccine. 2012;30(24):3546-56

16. Lazcano-Ponce E, Rivera L, Arillo-Santillan E, Salmeron J, Hernandez-Avila M, Munoz N. Acceptability of a human papillomavirus (HPV) trial vaccine among mothers of adolescents in Cuernavaca, Mexico. Arch Med Res. 2001; 32(3):243-7.

17. Woodhall SC, Lehtinen M, Verho T, Huhtala H, Hokkanen M, Kosunen E. Anticipated acceptance of HPV vaccination at the baseline of implementation: a survey of parental and adolescent knowledge and attitudes in Finland. J Adolesc Health. 2007;40(5):466-9.

18. Masika MM, Ogembo JG, Chabeda SV, Wamai RG, Mugo N. Knowledge on HPV vaccine and cervical cancer facilitates vaccine acceptability among school teachers in Kitui County, Kenya. PLoS One. 2015;10(8): e0135563.

19. Johnson DC, Bhatta MP, Gurung S, Aryal S, Lhaki P, Shrestha S. Knowledge and awareness of human papillomavirus (HPV), cervical cancer and HPV vaccine among women in two distinct Nepali communities. Asian Pacific journal of cancer prevention : APJCP. 2014;15(19):8287-93.

20. HPV vaccine introduced in Bangladesh [http://www.searo.who.int/ bangladesh/HPVvaccinelaunch/en/]. Accessed Aug 2017.

21. Islam RM, Bell RJ, Billah B, Hossain MB, Davis SR. Lack of understanding of cervical cancer and screening is the leading barrier to screening uptake in women at midlife in Bangladesh: population-based cross-sectional survey. Oncologist. 2015;20(12):1386-92.

22. Naing L, Winn T, Rusli BN. Practical issues in calculating the sample size for prevalence studies. Arch Orofac Sci. 2006;1:9-14.

23. Chan ZC, Chan TS, Ng KK, Wong ML. A systematic review of literature about women's knowledge and attitudes toward human papillomavirus (HPV) vaccination. Public health nursing (Boston, Mass). 2012:0(6):481-9.

24. Fu LY, Bonhomme LA, Cooper SC, Joseph JG, Zimet GD. Educational interventions to increase HPV vaccination acceptance: a systematic review. Vaccine. 2014;32(17):1901-20.

25. Akinyemiju TF. Socio-economic and health access determinants of breast and cervical cancer screening in low-income countries: analysis of the world health survey. PLoS One. 2012;7(11):e48834.

26. Arrossi S, Maceira V, Paolino M, Sankaranarayanan R. Acceptability and uptake of HPV vaccine in Argentina before its inclusion in the immunization program: a population-based survey. Vaccine. 2012;30(14):2467-74.

27. Kwan TT, Chan KK, Yip AM, Tam KF, Cheung AN, Lo SS, Lee PW, Ngan HY. Acceptability of human papillomavirus vaccination among Chinese women: concerns and implications. BJOG : an international journal of obstetrics and gynaecology. 2009;116(4):501-10.

28. Becker-Dreps S, Otieno WA, Brewer NT, Agot K, Smith JS. HPV vaccine acceptability among Kenyan women. Vaccine. 2010;28(31):4864-7.

29. Coleman MA, Levison J, Sangi-Haghpeykar H. HPV vaccine acceptability in Ghana, West Africa. Vaccine. 2011;29(23):3945-50.

30. Wong LP. Knowledge and attitudes about HPV infection, HPV vaccination, and cervical cancer among rural southeast Asian women. International journal of behavioral medicine. 2011;18(2):105-11.

31. Charakorn C, Rattanasiri S, Lertkhachonsuk AA, Thanapprapasr D, Chittithaworn S, Wilailak S. Knowledge of pap smear, HPV and the HPV vaccine and the acceptability of the HPV vaccine by Thai women. AsiaPacific journal of clinical oncology. 2011;7(2):160-7.

32. Raychaudhuri S, Mandal S. Current status of knowledge, attitude and practice (KAP) and screening for cervical cancer in countries at different levels of development. Asian Pacific journal of cancer prevention : APJCP. 2012:13(9):4221-7.

33. Montgomery MP, Dune T, Shetty PK, Shetty AK. Knowledge and acceptability of human papillomavirus vaccination and cervical cancer screening among women in Karnataka, India. Journal of cancer education : the official journal of the American Association for Cancer Education. 2015;30(1):130-7. 
34. Hussain S, Nasare V, Kumari M, Sharma S, Khan MA, Das BC, Bharadwaj M. Perception of human papillomavirus infection, cervical cancer and HPV vaccination in north Indian population. PLoS One. 2014:9(11):e112861.

35. Somannavar S, Lanthorn H, Pradeepa R, Narayanan V, Rema M, Mohan V. Prevention awareness counselling and evaluation (PACE) diabetes project: a mega multi-pronged program for diabetes awareness and prevention in South India (PACE- 5). J Assoc Physicians India. 2008;56:429-35.

36. Hopkins TG, Wood N. Female human papillomavirus (HPV) vaccination: global uptake and the impact of attitudes. Vaccine. 2013;31(13):1673-9.

37. Kane MA. Global implementation of human papillomavirus (HPV) vaccine: lessons from hepatitis B vaccine. Gynecol Oncol. 2010;117(2 Suppl):S32-5.

38. Garnett GP, Waddell HC. Public health paradoxes and the epidemiological impact of an HPV vaccine. Journal of clinical virology : the official publication of the Pan American Society for Clinical Virology. 2000;19(1-2):101-11.

39. Chidyaonga-Maseko F, Chirwa ML, Muula AS. Underutilization of cervical cancer prevention services in low and middle income countries: a review of contributing factors. Pan Afr Med J. 2015;21:231.

Submit your next manuscript to BioMed Central and we will help you at every step:

- We accept pre-submission inquiries

- Our selector tool helps you to find the most relevant journal

- We provide round the clock customer support

- Convenient online submission

- Thorough peer review

- Inclusion in PubMed and all major indexing services

- Maximum visibility for your research

Submit your manuscript at www.biomedcentral.com/submit
Biomed Central 